\title{
Mobile Phones Use among Health Care Workers and it's Possible Role in Spreading the Hospital Acquired Infections in Medical College Hospital, Rajnandgaon [C. G.], India
}

\author{
Siddharth Pimpalkar ${ }^{1}$, Dhiraj Bhawnani ${ }^{2} *$ and Om Singh $^{3}$
}

${ }^{1}$ Department of Microbiology, ${ }^{2}$ Department of Community Medicine, ${ }^{3}$ Govt. Medical College, Rajnandgaon (C.G.), India

*Corresponding author

\section{Key words}

Mobile phones,

Health Care

Workers, Hospital

acquired infections

Article Info

Accepted:

20 November 2018

Available Online:

10 December 2018

\section{A B S T R A C T}

In recent years, the use of mobile phones in the course of a working day has made mobile phones potential agents of microbial transmission. The increase use of mobile phones is seen as responsible for rise in community infection rates reported by ecological findings. Several etiologic agents of nosocomial infections (which contaminate mobile phone) are of various genera and species of bacteria, virus, fungi including Staphylococcus aureus, Ecoli, Klebsiella species, Enterococcus species, and Proteus species have been identified. So the present study was planned to assess the possibility of hospital acquired infection due to use of mobile phone in health care persons. The present cross sectional observational hospital based study has been conducted in Government Medical College, Rajnandgaon (Chhattisgarh) India, during the study period from January 2017 to October 2017. Sample size was fix at 110. Procedure was performed as per standard protocol. Data was compiled in MS-Excel and checked for it's completeness and correctness, then it was analysed by using suitable software. Present study shows that $63.636 \%$ of HCW's dominant hand and $56.36 \%$ of their mobiles phone had bacterial contaminations mostly with $S$. epidermidis. The sensitivity of gram negative bacilli towards ciprofloxacin, erythromycin, tetracycline and gentamycin were in the range of 32-85\%. All gram positive organisms were sensitive to vancomycin and sensitivity to ciprofloxacin, erythromycin and tetracycline was in the range of $91-98 \%$. We also found that $50 \%$ isolated Staphylococcus aureus were methicillin resistant Staphylococcus aureus (MRSA). It can be concluded from present study that mobile phones can act as source of hospital acquired infections and there is need to form definite policies for use of mobile phones in health care settings.

\section{Introduction}

The global system for mobile telecommunication was established in 1982 in Europe for the improvement in communication system. The first use of mobile phone in India was in 1995 and today 1033.20 million (May 2016) mobile phone users are in India ${ }^{1}$. In recent years, the use of mobile phones in the course of a working day has made mobile phones potential agents of microbial transmission. The increase use of 
mobile phones is seen as responsible for rise in community infection rates reported by ecological findings ${ }^{2}$. Since, hand washing may not usually be performed often enough and many people may use personal mobile phone in the course of a working day, the potential act of mobile phones as a source of microbial transmission is considerable ${ }^{2 .}$ Mobile phones are continuously used all day long but never cleaned, and there are no guidelines for proper disinfection and decontamination of mobile phones, further keeping them in pockets, handbags, and snug pouches increase the possibility of bacterial proliferation due to warmth and ideal condition ${ }^{3 .}$ Research has shown that the mobile phone could constitute a major health hazard. Microbiologists say that the combination of constant handling and the heat generated by the phones create a prime breeding ground for all sort of microorganism that are normally found on our skin ${ }^{4}$. The adult human skin has surface area of approximately $2 \mathrm{~m}^{2}$ which is constantly in contact with environmental microorganisms and become readily colonized by microbial species of about $10^{12}$ bacteria $^{5,6}$. Despite the tremendous advancement in modern medicine, nosocomial infections still cause a risk of increased mortality and morbidity to the hospitalized patient. The pathogens causing infections in patients also affects health care staff and visitors. Nosocomial infections caused by multidrug resistant gram positive organisms such as Staphylococcus aureus and Enterococcal species are a growing problem in many health care institutions ${ }^{7,8,9}$.

Several etiologic agents of nosocomial infections (which contaminate mobile phone) are of various genera and species of bacteria, virus, fungi including Staphylococcus aureus, E. coli, Klebsiella species, Enterococcus species, and Proteus species have been identified.

During every phone call the mobile phone come into close contact with strongly contaminated human body areas with hands to hands, and hands to other areas like mouth, nose and ears ${ }^{10}$. Mobile phones act as perfect habitat for microbes to breed, especially in high temperature and humid conditions ${ }^{11}$. HCWs' mobile phones may serve as reservoir of microorganisms that could be easily transmitted from the mobile phones to the HCWs' hands and therefore facilitate the transmission of bacterial isolates from one patient to another in different hospital wards. The wide spread use of mobile phones among medical personnel in hospitals is a matter of controversy. The question of concern is how to use the mobile phones sensibly getting their benefits and minimizing their risks ${ }^{12}$. Another point of view argues that, if mobile phones are used carelessly in surgical wards or intensive care units (ICU), they may act as a source of infection to patients while handling them, such as during dressing of surgical wounds ${ }^{13}$. Besides, there are no guidelines for disinfection of mobile phones that meet hospital standards. Moreover, the mobile phones are used routinely all day long and the same phones are used both inside and outside the hospital plying a possible role in spreading infections to the outside community ${ }^{14}$.

The present study was therefore planned to assess the possibility of hospital acquired infection due to use of mobile phone in health care persons in a tertiary care hospital of Rajnandgaon city (C.G.).

\section{Materials and Methods}

The present cross sectional observational hospital based study has been conducted in Government Medical College, Rajnandgaon (Chhattisgarh) India, during the study period from January 2017 to October 2017. Permission was taken from institutional ethics committee and informed written consent was taken from the subjects prior to conduction of the study. 


\section{Inclusion criteria}

Informed concent of HCW's.

\section{Exclusion criteria}

Non-willing HCW's.

As per available previous research, rate of mobile phone contamination was ranged from 70 to $95 \%$. So, $\mathrm{P}=50$ (rate of mobile phone contamination for over study) was taken.

$\mathrm{n}=4 \mathrm{pq} / \mathrm{1}^{2}$

$\mathrm{p}=50, \mathrm{q}=50,1$ is allowable error that is $20 \%$ of p. ${ }^{15}$

All the value was put and $n=100$ was obtained ( $\mathrm{n}=$ sample size) but as per need, more sample size for study was taken, that is, sample size of 110 (110 from mobile \& 110 from hands).

Before taking samples, both hands were washed thoroughly with soap and water and disinfected with alcohol.

From each individual, two swab samples (one from hand and other from mobile phone at the end of duty) with the help of sterile cotton swabs, moistened with normal $(0.85 \%)$ saline was taken.

In case of hand sample, palmar creases and interdigital spaces were also swabbed along with the tip of finger and palm of dominant hand, and sample was collected by gently rolling the swab stick over the areas for 6-7 seconds. Mobile phone swab was collected by rotating it on overall surface of the mobile phone. Swab was collected with all aseptic precautions.

The collected swabs were immediately transported to microbiology laboratory (Government medical college \& hospital) and inoculated on 5\% sheep blood agar and MacConkey Agar, streaked and incubated at $37^{\circ} \mathrm{C}$ for 24 hours and observed for the growth. After incubation the plates were observed for colony morphology and suitable tests like Gram stain, catalase, Coagulase and a panel of biochemicals (Indole production, Citrate utilization, motility using semisolid agar stab, Urease and TSI) were put up for identification. For example, if Gram positive cocci in clusters was recovered, catalase and slide coagulase along with mannitol fermentation (using 1\% w/v Andrade's indicator) were performed. If Gram negative bacilli were found, biochemical tests were carried out (sugars, indole test, MR test, urease test, citrate test). Then, according to Clinical and Laboratory Standards Institute (CLSI) guideline for isolation of organisms, antibiotic sensitivity test was performed by Kirby- Bauer Method. Antibiotic susceptibility test was performed by KirbyBauer disk diffusion method as per CLSI protocol using the following antibiotic disks: Cotrimoxazole $(25 \mu \mathrm{g})$, Amikacin $(30 \mu \mathrm{g})$ and Levofloxacin $(5 \mu \mathrm{g}$ ) disks (Hi Media Labs, New Delhi, India); Cefoxitin disk $(30 \mu \mathrm{g})$ was used to detect MRSA. ${ }^{(4)}$

Data was compiled in MS-Excel and checked for it's completeness and correctness, then it was analysed by using suitable software.

\section{Results and Discussion}

Types of bacterial organism isolated were shown in Table 1 and 2. Present study shows that $63.636 \%$ of HCW's dominant hand and $56.36 \%$ of their mobiles phone had bacterial contaminations mostly with $S$. epidermidis. Contamination with other nosocomial species (Staphylococcus aureus, Klebsiella pneumoniae, Enterococcus spp E.coli, Actinobecter, Pseudomonas Candida spp.) was $28.26 \%$ in dominant hand and $21.80 \%$ in mobile phones. 
Table 3 shows antibiotic sensitivity pattern of Gram negative organisms. The sensitivity of gram negative bacilli towards ciprofloxacin, erythromycin, tetracycline and gentamycin were in the range of $32-85 \%$.

Table 4 shows antibiotic sensitivity pattern of
Gram positive organisms. All gram positive organisms were sensitive to vancomycin and sensitivity to ciprofloxacin, erythromycin and tetracycline was in the range of 91-98\%. We also found that $50 \%$ isolated Staphylococcus aureus were methicillin resistant Staphylococcus aureus (MRSA).

Table.1 Types of organisms isolated from mobile Phones of HCWs

\begin{tabular}{|c|c|c|}
\hline S.N. & Organisms & No $(\%)(\mathrm{n}=110)$ \\
\hline 1 & Staphylococcus epidermidis & $62(56.36 \%)$ \\
\hline 2 & Staphylococcus aureus & $3(2.72 \%)$ \\
\hline 3 & E. coli & $3(2.72 \%)$ \\
\hline 4 & Klebsiella & $2(1.82 \%)$ \\
\hline 5 & Acinetobacter & $5(4.54 \%)$ \\
\hline 6 & Pseudomonas & $6(5.45 \%)$ \\
\hline 7 & Enterococci & $2(1.81 \%)$ \\
\hline 8 & Candida albicans & $3(2.72 \%)$ \\
\hline
\end{tabular}

Table.2 Types of organisms isolated from hands of HCWs

\begin{tabular}{|c|c|c|c|}
\hline S.N. & Organisms & No. & $\%$ \\
\hline 1 & Staphylococcus epidermidis & 70 & $(63.636 \%)$ \\
\hline 2 & Staphylococcus aureus & 1 & $(0.9 \%)$ \\
\hline 3 & E.coli & 2 & $(1.818 \%)$ \\
\hline 4 & Klebsiella & 10 & $(9.09 \%)$ \\
\hline 5 & Acinetobacter & 9 & $(8.181 \%)$ \\
\hline 6 & Pseudomonas & 3 & $(2.722 \%)$ \\
\hline 7 & Enterococci & 5 & $(4.545 \%)$ \\
\hline
\end{tabular}

Table.3 Sensitivity pattern of gram negative organisms from mobile phones and hands of HCWs (\%)

\begin{tabular}{|l|l|l|l|l|}
\hline Drug & E.coli & Klebsiella & Acinetobacter & Pseudomonas \\
\hline $\begin{array}{l}\text { Amoxicillin- } \\
\text { Clavulanic acid }\end{array}$ & 68.5 & 78 & 66.4 & 49 \\
\hline Co-trimoxazole & 54.7 & 52.8 & 42.5 & 32 \\
\hline Cefepime & 59 & 62 & 43.6 & 40 \\
\hline Ciprofloxacin & 75.8 & 83 & 80.2 & 72.4 \\
\hline Erythromycin & 75.5 & 74.8 & 38.4 & 33.3 \\
\hline Tertracyclin & 69.5 & 68.6 & 58 & 49 \\
\hline Gentamycin & 77.4 & 75.6 & 65 & 62.5 \\
\hline Amikacin & 82.6 & 83.3 & 72 & 70.6 \\
\hline
\end{tabular}


Table.4 Sensitivity pattern of gram positive organisms from mobile phones and hands of HCWs (\%)

\begin{tabular}{|l|}
\hline Drugs \\
\hline Amoxicillin- Clavulanic acid \\
\hline Co-trimoxazole \\
\hline Cloxacillin \\
\hline Cefoxitin \\
\hline Ciprofloxacin \\
\hline Erythromycin \\
\hline Tertracyclin \\
\hline Vancomycin \\
\hline
\end{tabular}

\section{Staphylococcus epidermidis}

\begin{tabular}{|r|l|r|} 
& $\begin{array}{l}\text { Staphylococcus } \\
\text { aureus }\end{array}$ & Enterococci \\
\hline 99 & 90.6 & 95.5 \\
\hline 91.6 & 70.6 & 96.2 \\
\hline 94.6 & 58.6 & 94.4 \\
\hline 98.6 & 80.6 & 95 \\
\hline 98 & 97.6 & 98 \\
\hline 94.6 & 94.6 & 91.2 \\
\hline 95.6 & 96 & 95 \\
\hline 100 & 100 & 100 \\
\hline
\end{tabular}

In concordance with our results, Ulger et al., stated that $94.5 \%$ of phones showed evidence of bacterial contamination and the isolated microorganisms were similar to hand isolates [16]. Jeske et al., found that the rate of bacterial contamination of HCWs' hands was $95 \%$ while that of mobile phone was $90 \%{ }^{[17]}$. Tambekar et al., stated that $95 \%$ of mobile phone showed bacterial contamination and among $S$. aureus isolates $83 \%$ were methicillin resistant ${ }^{[13]}$. Brady et al., showed that $89.7 \%$ of mobile phones were contaminated by bacteria ${ }^{[4]}$. Present study shows that $90.87 \%$ of HCW's dominant hand and $78.14 \%$ of their mobiles phone had bacterial contaminations. Although it is a normal skin flora it is responsible for a large number of hospital acquired infections and often proves difficult to treat because of the bacterium's genetic characteristics and growing resistance to high powered antibiotics ${ }^{18}$. Other isolated organisms were Staphylococcus aureus, Klebsiella pneumonia, Enterococcus spp, E.coli Pseudomonas spp, Candida spp etc. which are comparable with the findings of above mentioned studies.

The isolated microorganism from dominant hands correlated with the isolated ones from mobile phones in $63.36 \%$ of participants. We found that $50 \%$ isolated Staphylococcus aureus were Methicillin Resistant Staphylococcus aureus (MRSA). Methicillin resistant Staphylococcus aureus is a multidrug resistant and responsible for several difficultto-treat infections in humans. Methicillin resistant Staphylococcus aureus is especially troublesome in hospitals where patients are with open wounds, invasive devices and weakened immune systems. It is a wellknown fact that organisms like Staphylococcus aureus and coagulase negative staphylococci resist drying and thus can survive and multiply rapidly in the warm environments like mobile phones. Pseudomonas and Acinetobactor species isolated in the study showed multi drug resistance to commonly used antibiotics. Their ability to contaminate mobile phones is expected as they are multi drug resistant water and soil organisms and are responsible for infection in predisposed patients in the hospital.

In present study, organisms isolated from mobile phones are Staphylococcus epidermidis, Staphylococcus aureus, E.coli, Klebsiella, Acinetobacter, Pseudomonas, Enterococci, Candida albicans and all these microorganisms are established causes of Hospital Acquired Infections So, mobile 
phone can act as a source for spreading Hospital Acquired Infections.

The conclusion of the study are as follows:

1) Organisms isolated from mobile phones and hands of HCW'S are Staphylococcus epidermidis, Staphylococcus aureus, E. coli, Klebsiella, Acinetobacter, Pseudomonas, Enterococci Candida albicans.

2) Percentage of Staphylococcus epidermidis isolated from mobile phones is $56.36 \%$ and that from hands of Health Care Workers is $63.63 \%$. Contamination with other nosocomial species (Staphylococcus aureus, E. coli, Klebsiella, Acinetobacter, Pseudomonas, Enterococci Candida albicans) is $28.26 \%$ in hands of Health Care Workers and $21.80 \%$ in mobile phones.

3) The antibiotic sensitivity pattern of microorganisms isolates showed that most of them are sensitive to routinely used antibiotics but some of the isolates showed resistance to routinely used antibiotics eg MRSA.

It can be concluded from present study that mobile phones can act as source of hospital acquired infections and there is need to form definite policies for use of mobile phones in health care settings.

\section{Recommendations}

As restriction of using mobile phone while working hours is not the practical solution of the problem, ultrasonic cleaner is not available at most of places and HYGreen system is too new to install, we recommend simple measures like hand washing, cleaning of mobile phones with $70 \%$ isopropyl alcohol, using hand free mobile phone while working hours, well controlled infection control plan and regular training to $\mathrm{HCW}$ s to reduce the rate hospital acquired infection.

\section{Acknowledgement}

The authors are thankful to Faculties of Department of Microbiology and Community Medicine, Government Medical College, Rajnandgaon (Chhattisgarh) India, for their support during study period.

\section{References}

1. Kapdi M, Hoskote S, Joshi SR. Health hazards of mobile phones: an Indian perspective. JAPI 2008; 56:893-97.

2. Ibrahim T. A., Akenroye O. M.., Opawale B. O., and Osabiya O. J.(2013). Isolation and Identifcation of Bacterial Pathogens from Mobile Phones of Volunteered Technologists in Rufus Giwa Polytechnic, Owo, Ondo State. J Microbio and biotechnology, Volume 3| Issue 1:37-40.

3. Kabir A., Audu A., Olabisi A. and Akitoye C. (2009). The potential role of mobile phones in the spread of bacterial infections. J Infect Dev Ctries; 3(8):628632

4. Brady RR, Wasson A, Stirling I, McAllister C, Damani NN. Is your phone bugged? The incidence of bacteria known to cause Hospital Acquired Infection on healthcare workers' mobile phones. J. Hosp. Infect 2006; 62:123-125.

5. Todar K. Normal Bacterial Flora of Humans. Todar's Online Textbook of Bacteriology.

6. Mackowiak PA. The normal microbial flora. N. Engl. J. Med 1982; 307:83.

7. Singh, V., V. Aggarwal, S. Bansal, S.P. Garg and N. Chowdhary, 1998. Telephone mouthpiece as a possible source of hospital infection. J. Assoc. Phys. India, 46: 372373.

8. Kennedy, K.J., D.E. Dreimanis, W.D. Beckingham and F.J. Bowden, 2003. Staphylococcus aureus and stethoscopes. Med J. Aust., 178: 468. 
9. Elkholy Mt, Ewees IE. Mobile (cellular) phone contamination with nosocomial pathogens in Intensive care units. Med J Cairo Univ 2010; 2: 1-5.

10. Srikanth P, Ezhil R, Suchitra S, Anandhi I, Maheswari U, Kalyani J. the mobile phone in a tropical setting emerging threat for infection control; 13th International Congress on Infectious Diseases abstracts, Poster Presentations 2008; 10.

11. Bhattacharya K. Mobile phone and the surgeon-Is there a controversy? Indian J Surgery 2005; 67(1): 53-54.

12. Tambekar DH, gulhane PB, Dahikar Sg, Dudhane MN. Nosocomial hazards of doctor's mobile phones in hospitals. J Med $\begin{array}{llll}\text { Sci } & \text { 2008; } & \text { 8(1): }\end{array}$ http://dx.doi.org/10.3923/ jms.2008.73.762.

13. Karabay O, Koçoglu E, Tahtaci M.the role of mobile phones in the spread of bacteria associated with nosocomial infections.J Infect Developing Countries 2007; 1(1): $72-73$

14. GPI Singh, J. Bindra, R.K. Soni, M. Sood Prevalence of Periodontal Diseases in Urban and Rural areas of Ludhiana, Punjab. Vol. 30, No. 4 (2005-10 - 200512)

15. Ulger F, Esen S, Dilek A, Yanik K, gunaydin $\mathrm{M}$, leblebicioglu $\mathrm{H}$. are we aware how contaminated our mobile phones with nosocomial pathogens? Ann Clin Microbiol Antimicrob 2009; 8: 7. http://dx.doi.org/10.1186/1476-0711-8-7

16. Jeske., Tiefenthaler., Hohlrieder., Hinterberger and Benzer (2007). Bacterial contamination of anaesthetists' hands by personal mobile phone and fixed phone use in the operating theatre, Anaethesia; 62: (904-906).

17. Edward J. Lamb. Staphylococcus epidermidis characteristics. eHow contributor; accessed on, Dec. 2010, Available from http://www.ehow.com/ about_5459843_staphylococcusepidermidis-characteristics.html.

18. Fleming $\mathrm{K}$, randle J. toys-friend or foe? a study of infection risk in a paediatric intensive care. Paediatr Nurs 2006; 18: 1418

19. Yazhini J., Deepa and Kannagi (2013). Mobile phones as fomites in miocrobial dissemination, Int J CURR Sci, 5: 6-14.

20. Mukhtar G., Daniel A., and Zelalem A.. (2014), Prevalence and Antimicrobial Susceptibility Pattern of Bacteria Isolated from Mobile Phones off Health Care Professionals Working in Gondar Town Health Centers, ISRN Public Health volume, $6 \mathrm{Pp}$.

21. Kiran C., Chiranjay M., Bimala G., Priya B. and Indira B. (2009). Bacterial 'Cell' Phones: Do cell phones carry potential pathogens?. OJHAS Vol 8 Issue 1:1-5.

22. Usha A. Pushpa D., Aarti C., Sita M. (2009). Cellphones A modern stayhouse for bacterial pathogens. JK science; vol. 11.

23. Neha S., Aruna S., Parihar., Khatri., Arvind C. and Archana B. (2014). Prevalence and antibiotic pattern of microbes isolated from mobile phones of health care workers and non- health care workers, International $\mathrm{j}$ current microbio and applied sci; v 3:43-60. no 3:127-129

24. Lavanya., Manoj J., Virendra K. and Renu D. (2013). Accessories of health care workers: a boon or a curse to patients in pediatric ICU and Nursery?, International J Current Microbio and applied sci; 2:no 10:441-447.

25. Muhammad D., Saadullah., Hidayatullah., Haris K., Imran K., Nadeem Ullah., Hussain A., Ghazi R. and Sajad A. (2014). Antibiotic Susceptibility Patterns of Various Bacteria Associated with Cell Phone in a Khyber Teaching Hospital Peshawar (Pakistan), World Applied Sci J. 30 (12): 1712-1714

26. Tagoe., Gyande and Ansah (2011). Bacterial Contamination of Mobile Phones:. When Your Mobile Phone Could Transmit More Than Just a Call. Central microbiology.com, 2(10).2-13.

27. Munish G. and Asha G. (2009). Mobile phones as fomites in miocrobial dissemination, beware! Your phone is 
'bugged', Mobile phones of dental professionals a potential source of bacterial contamination -A Bacteriological Study. Indian JDental Sci. Vol.1 Issue 1.42-47.

28. Timothy J., Ameet S., Joyce R. and Scott W. (2012) Methicillin-resistant staphylococcal contamination of cellular phones of personnel in a veterinary, teaching hospital. www. Biomed centeral.com. 5:193

29. Gholamreza S., Nooshin T., Ali M., Touraj M. and Ehsan S. (2009). Bacterial Contamination and Resistance to Commonly Used Antimicrobials of Healthcare Workers' Mobile Phones in Teaching Hospitals, Kerman, Iran. Am J Applied Sci 6 (5): 806-810

30. Fatma U., Saban E., Ahmet D., Keramettin Y., Murat G. and Hakan L. (2009). Are we aware how contaminated our mobile phones with nosocomial pathogens?, Ann Clin Microbio and Antimicrob. 8:7:1-4.

31. Rawia I., Hatem I. B., Nabil M. A. (2012). Mobile phones and nosocomial infection; Int J Infect Control, v 8.1-5. 25.

32. Sweta S., Shashidhar A., Meghashyam B., SreeVidya K., and Kalyana C. (2010).
Mobile Phone Hygiene: Potential Risks Posed by Use, in the Clinics of an Indian Dental School; Journal of Dental Education; Volume 74 Number 10:11531158.

33. Harika A., Prashanth K., Ramana and Abhijitchaudhury (2013). Bacteriological study of microorganisms on mobiles and stethoscopes used by health care workers in emergency and ICUS, Int $J$ Pharmaceutical research and Bio Sci. Volume 2(3).

34. Sham B., Sundeep H. and Shailaja S. (2011), Potential of Mobile Phones to Serve as a Reservoir in Spread of Nosocomial Pathogens. Online Journal of Health and Allied Sciences, 10,Issue 2.1-3.

35. Kredit C. J., Kalkman M. J., Bonten A. C. M., Gigengock and Barach (2011). Handhygiene practices in the operating theatre: an observational study. British J Anaesthesia 107 (4): 553-8.

36. Khodavaisy., Nabili., Davari. Vahedi (2011). Evaluation of bacterial and fungal contamination in the health care workers' hands and rings in the intensive care unit, Original article JPREV HYG;52: 215-218.

\section{How to cite this article:}

Siddharth Pimpalkar, Dhiraj Bhawnani and Om Singh. 2018. Mobile Phones Use among Health Care Workers and it's Possible Role in Spreading the Hospital Acquired Infections in Medical College Hospital, Rajnandgaon [C. G.]. Int.J.Curr.Microbiol.App.Sci. 7(12): 2905-2912. doi: https://doi.org/10.20546/ijcmas.2018.712.331 